\title{
Broad-Spectrum of Sustainable Living Management Using Green Building Materials- An Insights
}

\author{
R. Sivarethinamohan ${ }^{1, a}{ }^{*}$, S. Sujatha ${ }^{2, b}$ \\ ${ }^{1} \mathrm{CHRIST}$ (Deemed to be University), Bangalore, Karnataka \\ ${ }^{2} \mathrm{~K}$.Ramakrishnan College of Technology, Trichy, Tamilnadu \\ amohan.dimat@gmail.com, bsujalalit@gmail.com
}

\begin{abstract}
Keywords: Life Cycle Assessment, Environmental Benefit, Economic Benefit, Sustainable Construction
\end{abstract}

\begin{abstract}
Owing to the recurrent modifications in the lifestyle and demands of humans the regular life of buildings is decreasing whereas the demolition or renovation of the buildings increases. Building materials and their components ingest just about 40 percent of world-wide vigour per annum in their life segments such as fabrication and procurement of building materials, construction and demolition. The development of the construction industry completely relies on the deployable resources. To abate the consumption of construction materials in current years, the construction industry has established an environmental track, which wishes to use naturally available materials. Reviving such technology, further developing this technology green building materials are paramount for constructing green buildings. Such a green-building constructional model does not require energy contributions frequently for production. The advantage of reducing the energy used in manufacturing, increases strength. Green Building material is one which utilizes less water, optimizes energy efficiency, conserves natural resources, generates less waste, produces less carbon dioxide emissions and provides improved space for inhabitants as compared to conventional buildings. It includes environmental, economic, and social benefits as well. This paper aims to provide knowledge about some of the green building materials that help for sustainable living. These elucidations can obligate a significant influence in contemporary construction owed to the escalation in the charges of traditional construction materials.
\end{abstract}

\section{Introduction}

Growth in the construction industry is influenced on depletable resources. Producing the conventional building materials lead to impact on environment that is irreversible. Traditional and conventional construction of buildings involves high usage of water, energy [1], carbon emissions and so on. Mainly it has a greater impact on environment. At this juncture using the eco-friendly material is a best way to construct the building.Eco-friendly exactly means earth-friendly or not harmful to the environment. This refers to products that that help in conserving resources which are depletable in nature and GO GREEN is a crux for all production arena. Eco-friendly produces prevent contributions to air, water and land pollution. Its benefits [2] may not be easily recognizable tangibly, but through design, construction and operations buildings that are constructed with green building materials reducing carbon emissions, energy and waste, conserving water and lowering humans exposure to toxins.In building, environmentally-friendly materials [3] (also identified as green building materials) are those which, perform actions of low environmental impact [4]. The green building material [3] actually either partially replacing the conventional building materials or completely replacing the conventional one. The rationale behind this paper is to highlight how sustainable building material 
can contribute to minimize the impact of environmental degradation, and produce healthy buildings which can be sustainable to the inhabitant as well as our environment

\section{Existing scenario of using conventional building material}

The materials used for constructing the building generally take various forms of challenges. The discharge or the emission from the building materials is given much consideration and the fabrication of building materials entails employ high energy and resources in relationship with building processes. Some environmental concerns are prominent among the by-products of construction material used in buildings. Several restrictions are also there in extracting the resources which are the main ingredients in the manufacturing of many materials. In addition to it, one should think about the infrastructure that supports the built environment. Lot more advancements pertains to the technology, are there that need to be addressed [5] to resolve the hitches of exhaustion of resources, corrosion, durability, lifespan of the materials, pollution and so on. Figure 1 shows the techno edge for the conventional building materials.

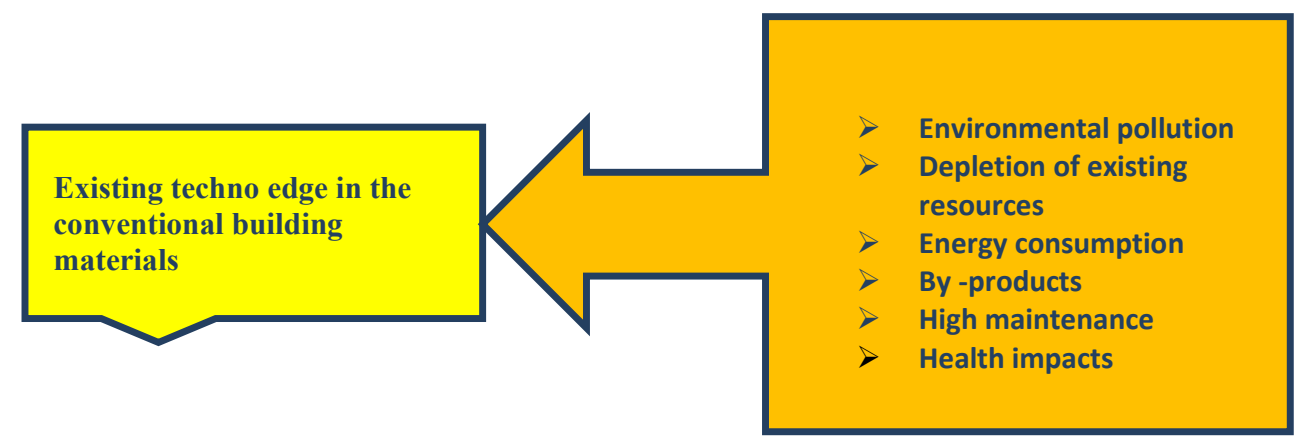

Fig.1 Current techno edge in the conventional building materials

\section{Properties of green building materials}

A green material is introverted that does the most with the smallest amount, fits most amicably surrounded by ecosystem processes, assists in eliminating the use of other materials and energy, and gives to the accomplishment of a service-based financial system. The advantages of using green building materials [6] over traditional materials are

- To achieve material efficiency which are everlasting, recyclable and reusable

- To design buildings in a conduct that consents for the use of smaller amount materials

- To take up processes that exploits less water, raw materials, and energy

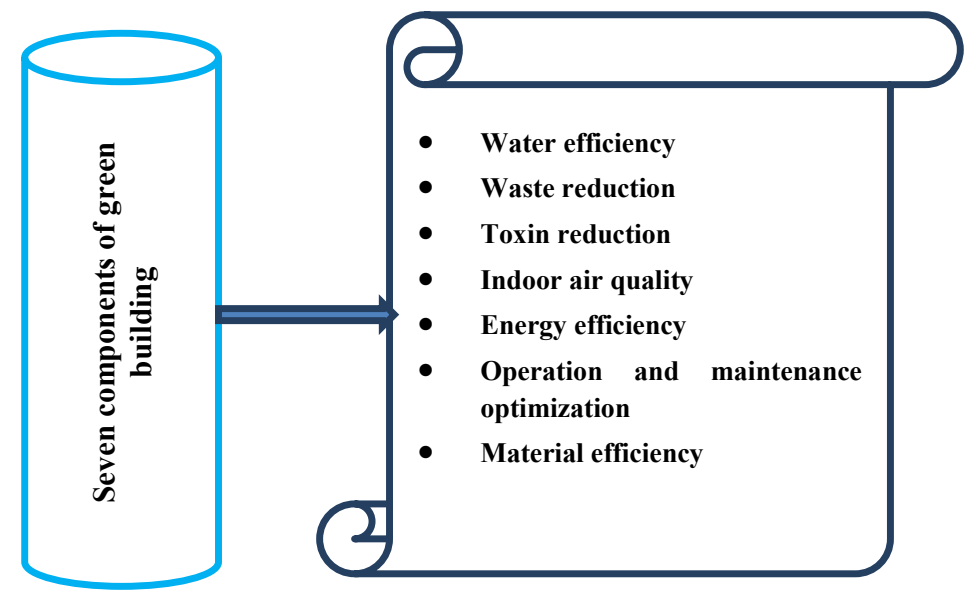

Fig. 2 Seven components of green building 


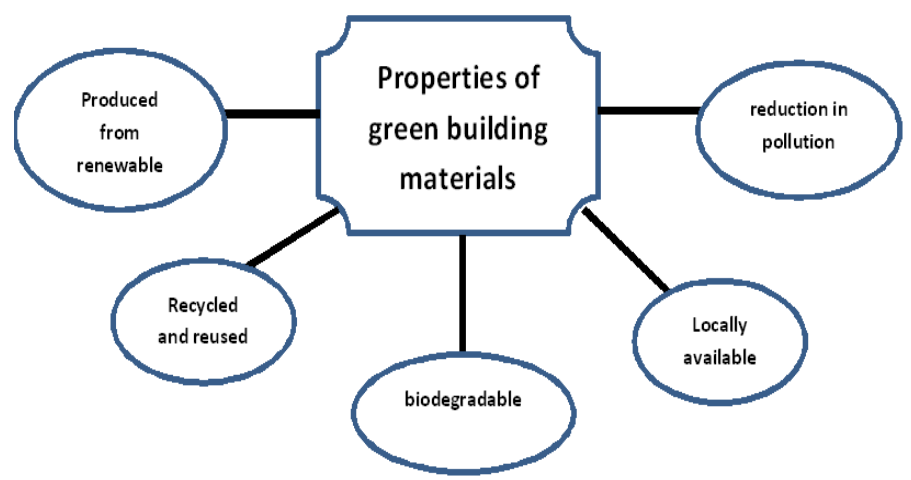

Fig. 3 Properties of green building materials

Green expertise in the construction business engages brings into being new buildings that integrate one or more characteristics of environmentally friendly way out [7] . Building green has upstretched the bar for the construction industry entirety by launching new standards for sustainability and at the same time liveability. It is particularly clear when we observe structures that are now being premeditated to allow buildings to be easily dismantled rather than demolished. Seven components of green building are shown in the figure 2. Properties of green building materials are elucidated in the figure 3.

\section{Evaluation of building materials for its sustainability}

The general categories of available material resources, and its performance and pollution analysis is based on

- Kinds of energy sources are used in producing the material [8]

- Kinds of pollution and waste used for production and transport generate, and how much harm will its disposal generate and could it obtainable locally.

- Recyclable throughout its entire product life and its durability.

The evaluation of green building materials is likely to [9] begin with conventional materials that are mostly used. However, in an evolution to sustainability, the process of evaluation must commence to consider more and more of materials that fit within environment [5]. To Evaluate the building products, it is essential the evaluation process should start from gathering of raw materials to their eventual clearance which could give us a better insight about the enduring costs of materials. During the production and selection of materials three stages of appraisal [10] could be done. The first and foremost stage is prior to constructing the building that is meant as pre building stage. Second stage is during the execution of the construction that is meant as ongoing building stage and the third stage is termed as post building stage. The first stage starts in finding unprocessed materials in nature and ends in transportation those materials to a building site. In between these two there exist manufacturing and packaging too. There is a much possibility of environmental destruction in the first stage. Second stage involves in assembling of material, maintaining and repairing the materials. This stage hangs on throughout the lifetime of the materials. In this second stage also waste generation is considered. The last and the least acknowledged stage is the third stage which is meant as post building stage. In this stage the performance of the materials will be low and it is the stage in which these materials should undergo recycling process. They could be reused into other goods or less can be thrown away. 


\section{Green building materials (eco- friendly materials) for construction}

Some of the green building materials have been discussed below (source:https://www.dumpsters.com/blog/green-building-materials) and have been displayed in the figures from figure 4 to figure 8 .

\section{Bamboo}

Bamboo plant grows easily and bamboo produces more oxygen than carbon dioxide as a consequence creating it a very eco-friendly and cost-effective construction material. It has a great durability as well.

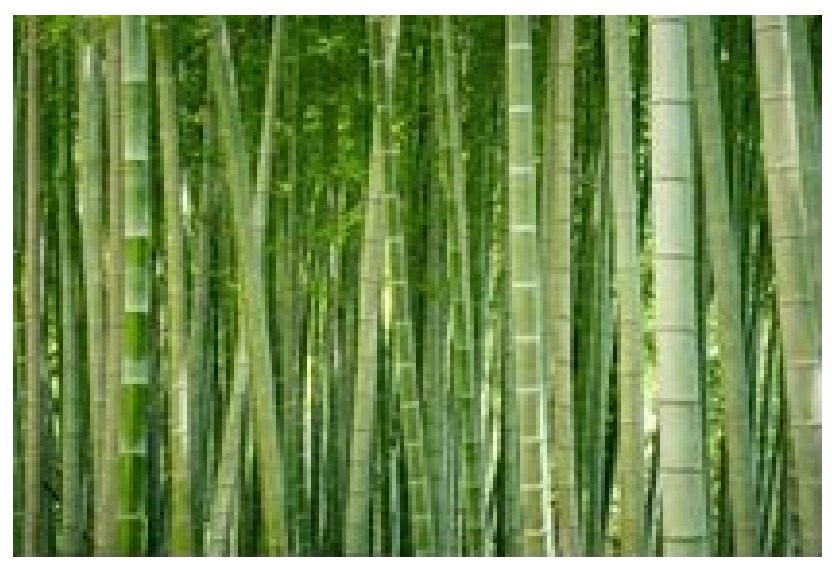

Fig.4 Bamboo(source:https://www.dumpsters.com/blog/green-building-materials)

\section{Engineered Wood}

Lot of wood gets wasted during the making of wooden boards from raw timber. This waste be capable of making engineered wood (which includes layers of wood and fillers similar to wood scraps and fibres). This is further used to make walls, doors and so on and which is in turn a eco-friendly material.

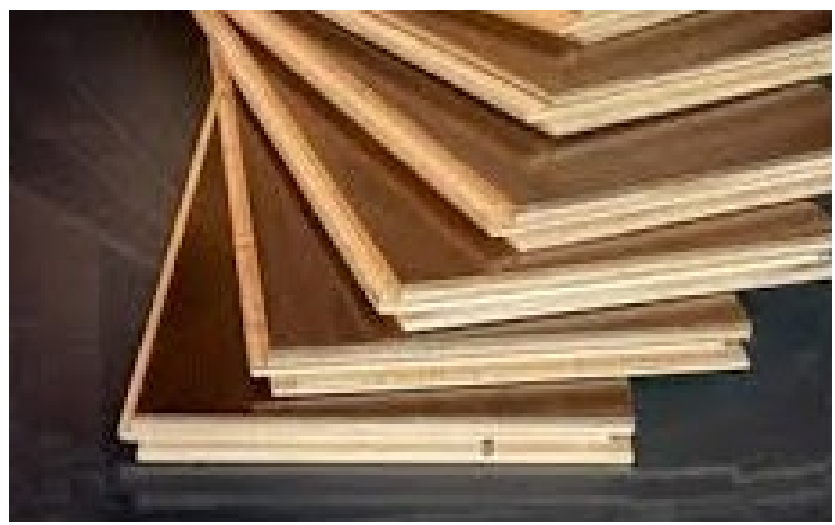

Fig. 5 Engineered Wood (source: https://www.dumpsters.com/blog/green-building-materials) 


\section{Earthen Materials}

Earthen materials are in use since the beginning of the construction. These include adobe bricks and rammed earth. Adobe bricks are fabricated from earth, comprising mainly of clay and straw or cow dung. Load bearing walls can be constructed using adobe bricks. Rammed earth is a kind of artificial rock that's formed by compacting ingredients such as dirt, gravel, sand, clay and silt. This kind of earth is fire resistant and rammed earth walls do not require periodical maintenance. Termite attach could be reduced by the usage of earthen material in building construction.

\section{Straw Bale}

Straw bale is one of the green building materials consisting of baled straw from rice, oats, wheat, barley, rye and so on. It possesses great insulating properties and acoustic properties. Since it has acoustic properties the wall that is built with straw bale will be completely soundproof.

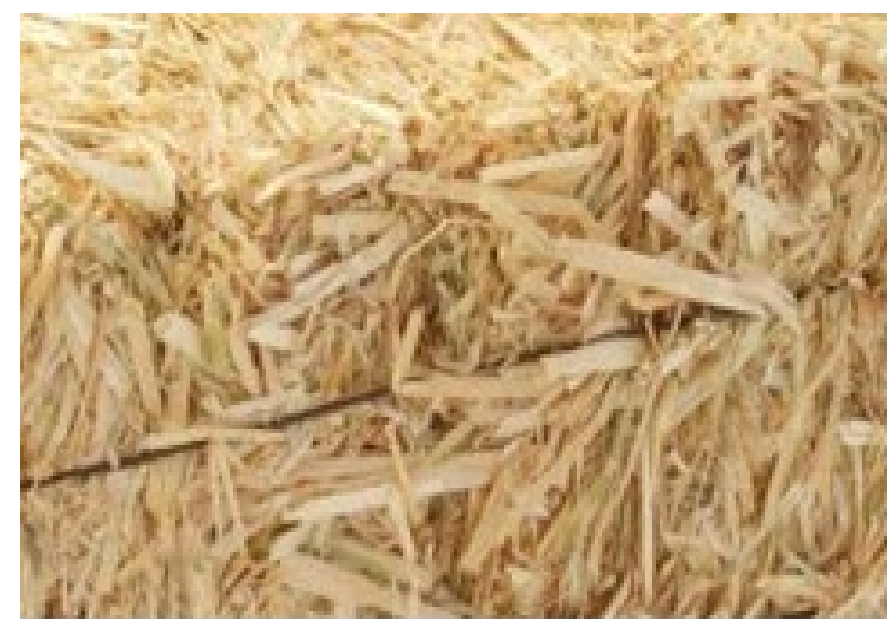

Fig. 6 Straw bale (source: https://www.dumpsters.com/blog/green-building-materials)

\section{Reclaimed Wood}

Those building that are constructed using reclaimed wood is the most environmentally friendly and have high accountability towards reducing the amount landfills and saving trees. It is a qualitative wood which could be obtained from sources like manufacturing units, old ships, withdrawn ships, godowns, warehouses and so on. The usage of reclaimed wood diminishes the demand for virgin wood which will eventually preserve the forests and thereby safeguards forest ecosystem.

\section{Cork}

In modern years, flooring with cork has happened to be more prevailing in residential and commercial areas. Cork is one among the sustainable building materials that does not hurt or injure trees. The tree bark could be stripped up to twenty times all through its life phase. Apart from the sustainable nature the cork has fire resistant quality as well. It also has resistant towards the liquids. Figure 7 portrays the cork. 


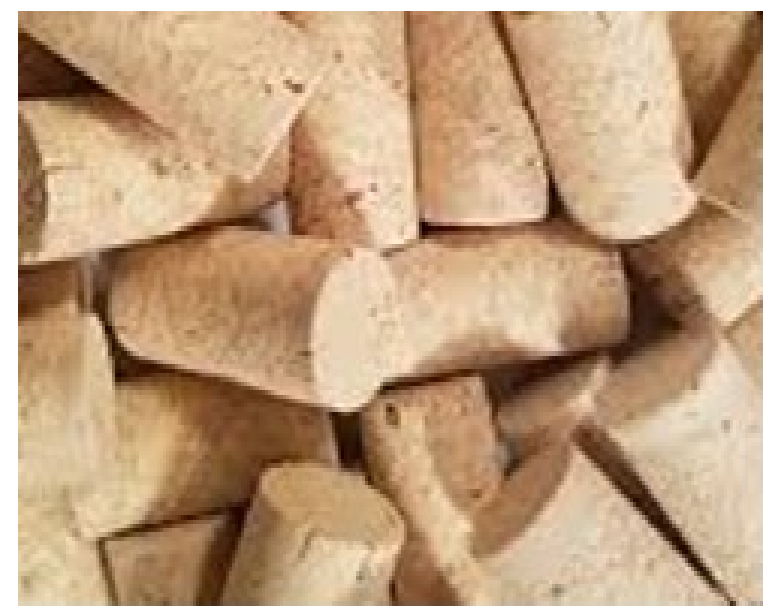

Figure 7.Cork(source:https://www.dumpsters.com/blog/green-building-materials)

\section{Mycelium}

It is fibrous material which resembles root of a tree. Mycelium are the root like fibres found on mushrooms and it is a vegetative part of fungus-like bacterial colony. Mycologist Philip Ross formerly tested with fungi and mycelium for his art fittings. This mushroom-based building material is able to hold up extreme temperatures, and degradable which is a better alternative to home insulation. Now days this kind of bio fabrication is ruling the sustainable construction world. Bricks that are prepared from mycelium are even act a bullet proof and even absorb carbon di oxide. Figure 8 indicating the wall made up of mycelium.

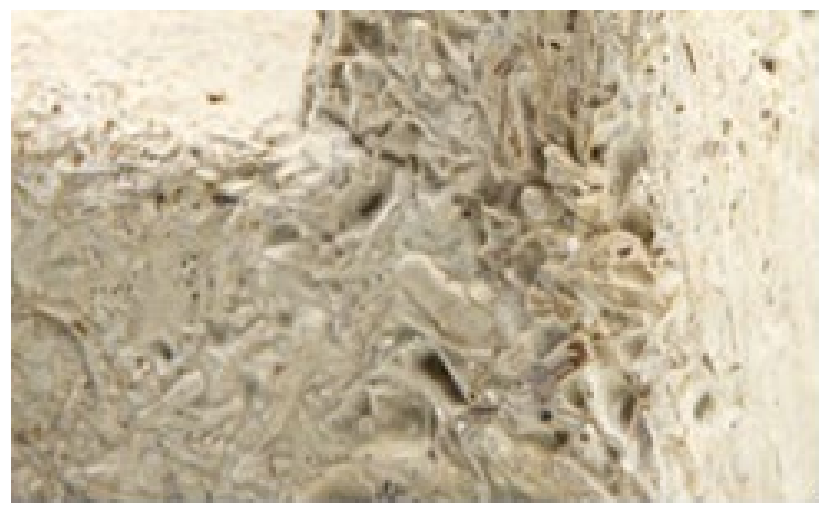

Fig.8. Mycelium wall(source:https://www.dumpsters.com/blog/green-building-materials) Ferrock and Recycled steel

In the context of manufacturing the concrete a material called as ferrock is fabricated by incorporating steel dust or ferrous rock which will be otherwise sent to the landfill. This additive produces iron carbonate with carbon dioxide. This alternative can be used to lay pathways, drive ways and even staircases. It is well known that 2,000 square-foot house entails up to 50 trees to build, whereas a frame made from recycled steel involves steel, equivalent of six crumbed cars. Above all steel has high recyclable value which can eventually

Trees could be saved and durability can be increased against earthquakes and high winds if steel beams are used for the framing process instead of wood. According to the Steel Recycling 
organization, since steel is 100 percent recyclable, it can significantly shrink the ecological shock of new construction.

Precast concrete also plays a major role in this context [11]. Light-emitting cement, Martian Concrete, Self-healing of cracked concrete using bacteria, Wood foam, Transparent wood are all newly created green building material [12].

Economic benefits of green construction using green building materials and risk in constructing green buildings

Green construction can end up with considerable economic savings by getting better employee yield, escalating benefits from up gradation in health and safety [2]. The cost components are manufacturing wages, office wages, utilities, building maintenance, equipment maintenance and initial investment are also reduced. It was found that "negligence of constructability in green designs" is the most severe risk factor. Design-related risk factors include the inexperience of designers in green projects, limited creativity and innovation in green designs, slow response to change orders, negligence of constructability in green designs, and negligence of material waste in green designs $[13,14]$.

\section{Conclusion}

Sustainability is a substitute measure for building materials and are usually preferred through some specifications related to functionality. It is also chosen based on technical and economical specifications. On the other hand, with sustainability as a vital dispute in the past few decades, predominantly in developed nations, the environmental stack of building materials as well happen to a more noteworthy prerequisite. The construction segment is directly or possibly indirectly generates a sizeable portion of the destruction on environment, which has become the key point to support sustainable development. It is finding more environmental friendly movements to construction and building. A building material which is said to be sustainable in nature needs to be exercised appropriately and contextually in each and every community growth. The purpose of sustainable building materials is not just lessening the transport costs, carbon emissions, and in most of the cases costs of the materials. It also recommends service and skills development opportunities for community members. In this paper how to find a better green material for the construction has been described. The risk that involves in constructing a green building using go green materials is also analysed here. Ultimately a thorough and steady action is needed today to protect our surroundings from further damage and to control the exhaustive usage of energy for the sustainable future.

\section{References}

[1] R.M.Pulselli, E. Simoncini, F.M.Pulselli and S.Bastianoni, Energy analysis of building manufacturing, maintenance and use: building indices to evaluate housing sustainability, Energy Build. 395 (2007) 620-8. https://doi.org/10.1016/j.enbuild.2006.10.004

[2] R.Ries, M. Bilec and N.M.Gokhan and K.L.Needy, The economic benefits of green buildings: a comprehensive case study, Eng. Eco. 513 (2006) 259-95. https://doi.org/10.1080/00137910600865469

[3] J.E.Fernandez, Material Architecture: Emergent Materials for Innovative Buildings and Ecological Construction ,Architectural Press: Amsterdam, Boston, Elsiever, 2006

[4] A.Karolides, Green Building Approaches Green Building: Project Planning and Cost Estimating,W iley, E-Book, Third Edition, 2002. 
[5] D.Sherwin, Reducing the cost of green, J. Green Build. 11 (2006) 46-54. https://doi.org/10.3992/jgb.1.1.46

[6] G.Polat and A.P. Gurgun ,Identification of Material-related Risks in Green, Building Procedia Eng. 196 (2017) 956-963. https://doi.org/10.1016/j.proeng.2017.08.036

[7] I.Cooper, Which focus for building assessment methods: Environmental performance or sustainability?, Build. Res. Inf. 27 4-5 (1999) 321-331.

https://doi.org/10.1080/096132199369435

[8] B.V. Venkatarama Reddy and K.Jagadish, Embodied energy of common and alternative building materials and technologies, Energy Build. 352 (2003) 129-37. https://doi.org/10.1016/S0378-7788(01)00141-4

[9] A.Muse and J.M. Plaut, 2006 An inside look at LEED: experienced practitioners reveal the inner workings of LEED, J. Green Build. 11 (2006) 3-8. https://doi.org/10.3992/jgb.1.1.1

[10] L.Bourdeau, Agenda 21 on sustainable construction, CIB Report Publication, 237,1999

[11]P.Wu and S.P.Low, Barriers to Achieving Green Precast Concrete Stock Management-a Survey of Current Stock Management Practices in Singapore, J. Constr. Manag. 14 (2014) 78-89. https://doi.org/10.1080/15623599.2014.899126

[12] P.De.Luca, I. Carbone and J.B.Nagy, Green building materials: a review of state Of the art studies of innovative materials, J. Green Build. 124 (2017) 141 -161.

https://doi.org/10.3992/1943-4618.12.4.141

[13]B.Ashuri and A.Durmus-Pedini, An Overview of the Benefits and Risk Factors of Going Green in Existing Buildings, J. Facil. Manag. 1 (2020) 1-15

[14]H.Ali and S.Alnusairat, Developing a Green Building Assessment Tool for Developing Countries-Case of Jordan, Build Environ . 445 (2009) 1053-1064.

https://doi.org/10.1016/j.buildenv.2008.07.015 